\title{
O perfil etiológico de lactentes que falham na triagem auditiva neonatal
}

\author{
LIMA, Maria Cecília M. P (PQ), LIMA, Suellen P. N (IC). \\ Resumo \\ Objetivo: Descrever as principais características etiológicas dos lactentes que permaneceram em alojamen- \\ to conjunto e que obtiveram falha no exame das emissões otoacústicas. Metodologia: Analisar protocolos \\ de triagem auditiva de lactentes que obtiveram falha no teste da triagem auditiva neonatal. Resultados: Das \\ 19.871 crianças triadas, $1.912(9,62 \%)$ obtiveram falha na primeira etapa da triagem, presença de indicador \\ de risco em 20,29\% da amostra sendo as etiologias com maior prevalência o Índice de Apgar alterado. \\ Conclusão: As etiologias conhecidas se encontram entre as causas pré-natais e perinatais o que nos le- \\ vam a conduzir a medidas de saúde que podem ser tomadas nesses instantes ajudando no prognóstico e \\ reabilitação de crianças com alterações auditivas.
}

Palavras Chave: Audição, Lactente, Triagem.

\section{Introdução}

Os estímulos sensoriais como a audição são considerados de extrema importância para o desenvolvimento infantil ${ }^{1}$. Dessa forma, a realização da triagem auditiva neonatal se faz necessário visto que esta ajuda a identificar precocemente uma perda auditiva possibilitando intervenção imediata. O registro das Emissões Otoacústicas Evocadas (EOAs) é o método para a detecção de alterações auditivas de origem coclear. É um teste objetivo, relativamente simples, rápido, não invasivo $^{2}$. O presente estudo possui como objetivo caracterizar a população das mães e descrever as principais características etiológicas dos lactentes que permaneceram em alojamento conjunto e que falham na primeira etapa da triagem auditiva.

\section{Resultados e Discussão}

A partir dos resultados obtidos pode-se observar que com relação à faixa etária materna, 28,04\% se encontravam entre 20 e 24 anos, tendo como nível de escolaridade ensino médio completo (37,93\%). Cerca de 19.871 crianças foram triadas sendo que destas $1.912(9,62 \%)$ obtiveram falha na primeira etapa do exame. Desse total, $54,13 \%$ dos lactentes era do gênero masculino e a maioria não possuía indicador de risco para perda auditiva, com total de $1172(61,30 \%)$ casos. Os que possuíam indicador perfez um total de $38,70 \%$. Dentre as etiologias mais encontradas estavam Apgar de 0 a 4 no primeiro minuto, infecções congênitas (TORCH), uso de medicamento ototóxico na gestação, uso de álcool e drogas durante a gestação, malformações congênitas, hiperbilirrubinemia e casos de deficiência auditiva na família.

Figura 1. Etiologias prevalentes.

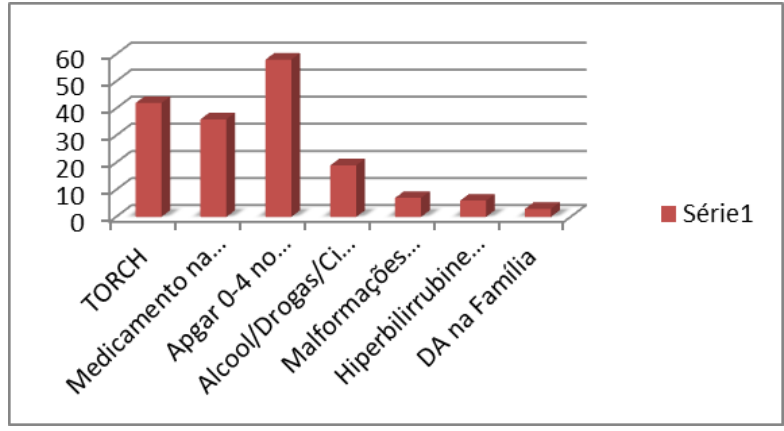

Conclusões

A análise dos resultados permite inferir que as etiologias conhecidas se encontram entre as causas de falha na triagem auditiva e que podem auxiliar em medidas de saúde para evitar o aparecimento de perdas auditivas de aparecimento tardio.

\section{Agradecimentos}

A pró-reitoria de pesquisa e ao órgão de fomento SAE-UNICAMP.

1PIALARISSI, Paulo. Roberto. GATTAZ, Gilberto. Emissões Otoacústicas: Conceitos Básicos e Aplicações Clínicas, Archives international of Otorhinolaryngology, Abril/ Junho, 1997, vol.1.

${ }^{2}$ RUSSO, Iêda C. Pacheco. SANTOS, Teresa M. Momensohn. Audiologia Infantil, São Paulo, 1996, $4^{a}$ edição. 